Please quote as: Schöbel.S. ; Söllner, M. \& Leimeister, J. M. (2016): The Agony of Choice - Analyzing User Preferences regarding Gamification Elements in Learning Management Systems. In: International Conference on Information Systems (ICIS), Dublin, Ireland. 


\title{
The Agony of Choice - Analyzing User Preferences regarding Gamification Elements in Learning Management Systems
}

\author{
Completed Research Paper
}

\author{
Sofia Schöbel \\ University of Kassel \\ Information Systems \\ Pfannkuchstraße 1, 34121 Kassel, Germany \\ sofia.schoebel@uni-kassel.de
}

\author{
Matthias Söllner \\ Jan Marco Leimeister \\ University of Kassel/ University of St. Gallen \\ Information Systems/ Institute of Information Management \\ Pfannkuchstraße 1, 34121 Kassel, Germany/ Unterer Graben 21, 9000 St. Gallen, \\ Switzerland \\ [soellner, leimeister]@uni-kassel.de/[matthias.soellner, \\ janmarco.leimeister]@unisg.ch
}

\begin{abstract}
Gamification is an approach to motivate users of information systems by implementing game elements. Despite its potentials, the use of gamification in practice has also received criticism because most gamification elements are integrated into systems without considering the preferences of the respective users and without considering contextual aspects. Hence, we aim at identifying which elements users of learning management systems prefer. Furthermore, we want to identify their preferences regarding the amount and combination of gamification elements. To identify user preferences, we conducted a discrete choice task among learning management system users following the best-worst scaling method. Our results show that users prefer a bundle of four gamification elements: level, goals, status, and points. This is especially interesting since popular elements, such as a leaderboard or badges, are not most preferred. This highlights the need to consider user preferences and contextual aspects to ensure a successful implementation of gamification elements.
\end{abstract}

Keywords: Gamification, Gamification Bundles, User Preferences, Learning Management Systems, Best-Worst Scaling

\section{Introduction}

One prominent example of information systems (IS) are learning management systems (LMS) (Alavi and Leidner 2001). LMSs are widely used in businesses and educational institutions such as universities (Alavi and Leidner 2001). LMSs are often referred to as technology-meditated learning, e-learning, and virtual learning, and they are used to support students or employees in improving their learning (Urh et al. 2015). Because LMSs have shown a high drop-out rate, prior research highlighted that relying on mechanics of computer games is one effective way to influence and change the behavior of LMS users (Bedwell et al. 2012; Demetrovics et al. 2011; Gupta and Bostrom 2009; Santhanam et al. 2016; Shang 
and Lin 2013). People like to play games during their spare time, whether it is at home on the television or on their way to work on a mobile device (Attali and Areli-Attali 2015). Because games are successful in our everyday life, the concept of gamification has been developed. Gamification describes the use of game design principles in non-gaming activities to improve user engagement (Deterding et al. 2011; Thiebes et al. 2014). Gamifying an LMS is about adding game layers to it rather than developing a particular game that connects learning and playing a game (Santhanam et al. 2016; Urh et al. 2015). More precisely, game mechanics (e.g., points and badges), game dynamics (e.g., competition and collaboration), and mini games can be used to gamify an LMS (Biro 2013; Blohm and Leimeister 2013; Santhanam et al. 2016; Zaman et al. 2012).

While game design principles are increasingly used in learning environments, the concept, meanwhile has to face some criticism in research and practice (Gartner 2012; Santhanam et al. 2016). Contrary to the forecasts, the positive effects of gamification are often short-term in practice (Christy and Fox 2014). Gartner was one of the first to highlight the problems in the implementation of gamification in practice. Gartner predicted in 2012 that eighty percent of all gamification projects in 2014 would not be successful (Gartner 2012). From today's perspective, Gartner's assumptions can be confirmed, as most gamification approaches still have some major weaknesses (Fogel 2015). Despite some criticism about the overall gamification approaches, gamification projects often fail due to a missing consideration of the needs and preferences of system users. Fleming (2014) and de-Marcos et al. (2016), for example, highlight that current gamification concepts are designed without knowing which gamification elements users really want to have implemented. With regard to this, Santhanam et al. (2016) explain that there might be no one-size-fits-all solution for gamification designs. This criticism is, for example, reflected by the observation that the amount of gamification elements in previous studies varies from one gamification element (Davis and Singh 2015; Hamari 2013; Pedro et al. 2015) to five or more elements (Ibánez et al. 2014; Peham et al. 2014; Simoes et al. 2013). Consequently, a possible explanation for the limited success of gamification in practice is that different gamification elements are combined and implemented without considering the preferences of users (de-Marcos et al. 2016; Fleming 2014). In this context, Schlagenhaufer and Amberg (2015) note that there are only few empirical studies on user preferences and requirements when aiming to use game elements in a non-entertainment-based context. Seaborn and Fels (2015) revealed this point for future research. They explain that it is necessary to determine the usefulness of particular gamification elements and that future research should aim at isolating the most promising and least promising gamification elements for a particular context. This can be supported by Hanus and Fox (2015), who explain that it is more important to investigate specific gamification elements rather than an overarching concept. Furthermore, although gamification can have positive impacts on user engagement, more research has to investigate the role of contextual and situational aspects, as they determine the motivational affordance of gamification element designs (Mekler et al. 2015).

All these findings indicate that more research needs to be conducted to determine the usefulness of particular gamification elements (Hanus and Fox 2015). Hence, research should aim at isolating the most promising and least promising gamification elements for a particular context by considering the preferences of users (Seaborn and Fels 2015). Furthermore, future research has to determine the appropriate amount of gamification elements. This is necessary because motivational effects can be reduced by implementing a greater amount of gamification elements in an LMS (Hanus and Fox 2015). Hence, the goal of our research study is twofold. In a first step, we want to find out which gamification elements users of an LMS prefer. By isolating which specific gamification elements users prefer, we can better understand how to create a gamified LMS that increases engagement and motivation (Hanus and Fox 2015). Referring to this, we still do not know the relationship and its meaning between specific gamification elements and learning (de Santana, Sivaldo J. de et al. 2016). Furthermore, we want to find out how many gamification elements users would implement in an LMS and which elements they would combine to a bundle of elements. Consequently, our paper focuses on the following research questions:

\author{
RQ1: Which gamification elements do users of LMSs prefer? \\ RQ2: Which gamification bundles do users of LMSs prefer? \\ $R Q$ 2.1: How many gamification elements would users of LMSs combine? \\ $R Q$ 2.2: Which gamification elements would users of LMSs combine?
}


To determine which gamification elements users of LMSs prefer, we rely on a discrete choice task that follows the best-worst scaling method (Lansing et al. 2013; Louviere et al. 2013). Due to the results of our best-worst scaling, we can give theoretical and practical implications. The results show that users of LMSs prefer a bundle of four gamification elements. More precisely, they want to combine the gamification elements level, points, status, and goals. Furthermore, our results indicate that users of LMSs like to compete against themselves instead of competing against others. To achieve our desired goal, the remainder of this paper is structured as follows: First, we present the related work regarding research on gamification and LMSs. Afterwards, we provide details on our research design, including data collection and analysis, before we present our results. Next, we discuss the results of our analysis and derive implications for both theory and practice. Furthermore, we discuss the limitations of our study and areas for future research before we conclude our paper.

\section{Theoretical Background on Gamification}

\section{Gamification}

Gamification has its origin in the use of games in daily life. More precisely, people like to play games during their spare time, whether it is at home on the television or on their way to work on a mobile device (Attali and Areli-Attali 2015). In total, there are two different ways to use games in IS. One possibility of integrating games into IS is the use of serious games (Stapleton 2004). Serious games can be defined as follows: "A mental contest, played with a computer in accordance with specific rules that uses entertainment to further government or corporate training, education, health, public policy, and strategic communication objectives" (Zyda 2005). Hence, serious games have been developed for the broader purpose of training and behavior change in many different areas (Connolly et al. 2012). According to this, playing serious games is increasingly linked to learning, with some studies showing the positive learning outcomes that playing digital games can have (Connolly et al. 2012; Stapleton 2004; Wouters et al. 2013).

Unlike serious games, gamification refers to the use of different elements instead of developing an entire computer game. The term gamification originated in the digital media industry (Deterding et al. 2011) and was first used in 2008, though the concept gained recognition in the second half of 2010 when it became a topic in conference presentations and was adopted by the industry (Thiebes et al. 2014). Even though a limited number of definitions of the term gamification are available, two of the mostly widespread definitions are outlined by Deterding et al. (2011) and Hamari et al. (2014). Deterding et al. (2011) define gamification as an "informal umbrella term for the use of video game elements in non-gaming systems" in order to "improve user experience and engagement". Summarized, it can be defined as the use of game design elements in non-game contexts. On the other hand, Hamari et al. (2014) define the term as a "process of enhancing services with (motivational) affordances in order to invoke gameful experience and further behavioral outcomes" (Hamari et al. 2014). Hence, the authors take their definition further and elaborate on it by including certain characteristics. They suggest that gamification contains three parts, namely the implemented motivational affordance, the resulting psychological outcome, and further behavioral outcomes. Finally, Thiebes et al. (2014) characterize gamification as the application of game design principles to existing organizational, real-world problems, situations, or processes. Referring to this, Blohm and Leimeister (2013) classify gamification elements into three groups: mechanics, dynamics, motives. Mechanics are constructing elements for designing a gamified IS and dynamics describe the effects of mechanics on the subjective user experience over time. Motives are internal driving forces that encourage people to act, such as achievements or social exchanges (Blohm and Leimeister 2013; Turabik and Baskan 2015). Gamification elements are mostly clustered into a bundle of elements and intend to motivate and engage IS users in a regular system use (Aparicio et al. 2012). To combine the definitions stated above and to identify a definition that fits our research goal, gamification can be seen as the use and combination of game mechanics (in the following referred to as gamification elements) in a non-game context for designing a gamified LMS (Blohm and Leimeister 2013; Turabik and Baskan 2015) that ideally cause a resulting psychological outcome by leading to motivational incentives (Deterding et al. 2011; Hamari et al. 2014).

Referring to motivation, playing games motivates especially intrinsically. Regarding this, intrinsic motivation refers to a condition that can be achieved if an individual has fun while doing an activity (Lafrenière et al. 2012). Additionally, intrinsic motivation means that an individual thinks an activity is 
challenging, useful, and interesting. The same intrinsic motivational effects can be caused if an individual can exercise power or make progress in an activity. Extrinsic motivation, on the other hand, is combined with a reward. This reward can be earned by successfully finishing an activity (Lafrenière et al. 2012). Furthermore, extrinsic motivation can be stimulated by the avoidance of punishment. With regard to this, gamification elements such as level, goals, status, and leaderboard encourage intrinsic motivation (Attali and Areli-Attali 2015; Hanus and Fox 2015; Melero et al. 2015; Passos et al. 2011), whereas elements such as points, badges, and virtual goods encourage extrinsic motivation (Attali and Areli-Attali 2015; Bunchball 2010; Hamari 2013). Considering the meaning of motivation, many research studies find positive effects of gamification in motivating system users to regularly use the system (Bedwell et al. 2012; Demetrovics et al. 2011; Lee et al. 2013; Shang and Lin 2013; Sigala 2015). Furthermore, a regular system use supported by gamification can have positive effects on the learning outcomes of IS users (Urh et al. 2015).

With regard to the use of gamification elements, previous gamification studies identified different lists of gamification elements. Thiebes and Scott (2014) identified a list of 31 different gamification elements. Hsu et al. (2013) as well as Hamari et. al (2014) identified only nine different kinds of gamification elements. Bedwell (2012), for example, identified different game attributes in his research studies. Overall, he identified 19 different attributes. Scheiner (2015), on the other hand, identified seven gamification elements. Finally, de-Marcos et al. (2016) identified a list of 29 elements. Additionally to the different amounts of elements, they are also somehow categorized in different ways. Due to this, there are significant differences regarding the use and combination of gamification elements in IS. For example, Thiebes et al. (2014) use the gamification element competition as an element. In other studies, competition is used as a category, not as an element. Hsu et al. (2013) use achievement for categorizing the gamification elements rewards, goals, reputation, and status. Thiebes et al. (2014) use achievement as gamification element in the category of rewards, and de-Marcos et al. (2016) use achievement as gamification element without any categorization. Furthermore, Scheiner (2015), for example, classifies level, badges, points, and story as game mechanics, whereas Bedwell (2012) classifies story as a game attribute, and de-Marcos et al. (2016) classify points as features.

Based on the different kinds of categorizations and amounts of gamification elements, we conducted a literature review to analyze which and how many gamification elements had been used in previous research studies. In our literature review, we focused on studies that used gamification elements in LMSs. Therefore, we identified 36 studies that used the following gamification elements: points, goals, time pressure, loss aversion, avatar, level, leaderboard, badges, achievements, progressive disclosure, progress bar, virtual goods, status, story, fantasy, challenges and, rewards. In six research studies, the authors used just one gamification element. Three of the five studies used different variations of badges for motivating users (Davis and Singh 2015; Hamari 2013; Pedro et al. 2015). On the other hand, Jones (2014) used goals in his research study, whereas Wang (2015) used status, and Fernandes (2012) integrated a point system into his research study. Most gamification elements were combined by Liu et al. (2013) and Simoes et al. (2013) who used seven different gamification elements in their research study. Additionally, we could identify studies that integrated an amount from two to seven gamification elements. A list with all studies that used two or more gamification elements can be seen in the appendix (Table 9). Referring to the selected gamification elements, most studies used the gamification elements points (20), badges (16), and leaderboard (13). Referring to our research goal, no study selected gamification elements in consideration of the needs and preferences of users.

In our research study, we focus on ten gamification elements in total (see Table 1). Due to the varying approaches of previous research studies, we defined characteristics for the exclusion of some gamification elements. As mentioned above, we focus on game mechanics. The gamification element achievement was excluded because it can be categorized as motive (Blohm and Leimeister 2013). The gamification element challenges was excluded because it belongs to gamification dynamics (Blohm and Leimeister 2013). Furthermore, we did not consider gamification elements such as story and fantasy because they belong to the design of a serious game ( $\mathrm{Li}$ et al. 2012). We excluded the gamification element progressive disclosure because it needs the presence and use of other elements (Hew et al. 2016). The gamification element progress bar was excluded due to the similarity to the gamification element status. Finally, we excluded the gamification element rewards because this element was used as additional points (Liu et al. 2011). A description of the ten gamification elements we used in our research study can be seen in Table 1 . 
Table 1. Gamification Elements Used in Our Research Study

\begin{tabular}{|l|l|}
\hline $\begin{array}{l}\text { Gamification } \\
\text { Element }\end{array}$ & Description \\
\hline Goals & $\begin{array}{l}\text { Goals can be reached by successfully completing a task or activity (Domínguez et al. } \\
\text { 2013). Mostly, they are adapted as challenge for the user (Passos et al. 2011). }\end{array}$ \\
\hline Time Pressure & $\begin{array}{l}\text { Creating pressure on given tasks or activities by integrating an hour glass or a } \\
\text { counter. Hence, a user has to complete a task as fast as possible (Burgers et al. 2015). }\end{array}$ \\
\hline Points & $\begin{array}{l}\text { Points are rewards given for successfully performing a task or an activity. They are } \\
\text { mostly a part of an overall point score (Attali and Areli-Attali 2015). }\end{array}$ \\
\hline Badges & $\begin{array}{l}\text { A badge is a reward that is given for fulfilling activities or tasks outside the scope of } \\
\text { the core activities (Hamari 2013). }\end{array}$ \\
\hline Status & $\begin{array}{l}\text { A status informs users about their current activities and the progress they made in a } \\
\text { system by giving feedback (Passos et al. 2011). Some studies use the term feedback } \\
\text { instead of status (Burgers et al. 2015). }\end{array}$ \\
\hline Leaderboard & $\begin{array}{l}\text { A leaderboard offers the opportunity to compare own results with the results of other } \\
\text { IS users (Hanus and Fox 2015). }\end{array}$ \\
\hline Level & $\begin{array}{l}\text { A level indicates the progress of a user regarding a certain task or activity. } \\
\text { Furthermore, it indicates the proficiency regarding the overall performance in a game } \\
\text { over time (Melero et al. 2015). }\end{array}$ \\
\hline $\begin{array}{l}\text { Virtual } \\
\text { Character }\end{array}$ & $\begin{array}{l}\text { A virtual character accompanies a system user during the use of a system, it is similar } \\
\text { to a kind of tutor (Christy and Fox 2014; Davis and Singh 2015; Domínguez et al. } \\
\text { 2013; Filsecker and Hickey 2014; Pedro et al. 2015; Simoes et al. 2013; Wang and } \\
\text { Hou 2015). In some cases, they represent the users (Passos et al. 2011). }\end{array}$ \\
\hline Loss Aversion & $\begin{array}{l}\text { Loss aversion influences the user not by a reward, but by a punishment (Liu et al. } \\
\text { 2013) if a task or activity is not achieved. }\end{array}$ \\
\hline Virtual Goods & $\begin{array}{l}\text { Virtual goods are non-physical and intangible objects that can be earned by } \\
\text { successfully completing a task or activity (Bunchball 2010). }\end{array}$ \\
\hline
\end{tabular}

In summary, despite the different amounts of integrated and analyzed gamification elements, all previous research studies draw other conclusions due to their different research results. Hence, some research studies may not be successful due to their missing consideration of user preferences. According to this, research should focus more on the selection, amount, and combination of gamification elements in different contexts by considering the usefulness of particular gamification elements. Referring to this, Seaborn and Fels (2015) imply that future research should aim at isolating the most and least promising game elements for a particular context. Hence, with our research, we want to focus on the preferences of LMS users with regard to the type of gamification element, the amount, and combination.

\section{Learning Management Systems}

According to Hess et al. (2014), LMSs have a utilitarian purpose and are used on a voluntary basis. They can be defined as "an environment in which users' interactions with learning materials, peers, and/or instructors are mediated through technologies" (Alavi and Leidner 2001; Sims 2003). Therefore, a virtualbased classroom can become a virtual learning space that can furthermore be supported by collaborative learning structures (Arbaugh 2000). In terms of learning materials, two forms of student-content interaction can be identified: those initiated by a system user and those initiated by the information system (Evans and Gibbons 2007). Overall, LMSs are used to support students or employees to improve their learning (Urh et al. 2015). Therefore, it enables learning from anywhere and at any time. The increasing number of interdisciplinary programs leads to different kinds of learning situations that can be handled more effectively by using gamification (Urh et al. 2015). Thus, gamification is a possible approach to motivate users to use systems more regularly (Scheiner and Witt 2013). Hence, gamifying learning has two purposes (Ibánez et al. 2014). The first is to encourage desired learning behavior. The second is to engage the users in learning by the use of learning materials such as tutorials or digital documents. Therefore, engagement has been proved to be positively correlated with the outcomes of user success, such as user satisfaction and academic achievements (Ibánez et al. 2014). Accordingly, gamification 
increases the motivation of users by providing different gamification elements, by making an activity or task more fun and engaging, and by encouraging exchange between users. In the following, we describe our research method for the identification of user preferences.

\section{Methodology}

\section{Best-Worst Scaling}

Different approaches are available for assessing user preferences in general. A popular technique is conjoint analysis, which concentrates on combining a limited number of attributes (Green and Srinivasan 1990) and is often used in marketing for example for evaluating the price or design of a product (Green and Srinivasan 1990). However, conjoint analysis does not work well for a large number of attributes (seven or more) (Matzner et al. 2015). Another possibility of identifying user preferences for a large number of attributes is the self-explicated approach, which contains several methods such as ranking, rating, maximum difference scaling, or O-methodology (Matzner et al. 2015). In regular ranking mechanisms, respondents are asked to rank attributes from most attractive to least attractive (Cohen 2003). Hence, the resulting data is ranked ordinally. By using a rating measurement, respondents rate each item on a scale from, for example, 1 least attractive to 10 most attractive (Bacon 2003). Maximum difference scaling (MaxDiff) is a method for paired comparisons where participants have to choose a preferred attribute from a pair of attributes (Thurstone 1927). Finally, Q-methodology enables individual rankings for a factor analysis in order to reveal correlations between different kinds of profiles (Stephenson 1935).

The aim of our research study is to identify which gamification elements users of LMSs prefer. As mentioned before, we want to compare each gamification element individually, which is why conjoint analysis seems to be inappropriate as a first analysis. Using simple ranking mechanisms seems to be not suitable because they suffer from potential order effects and a lack of ties and absolute scores (Cohen 2003). Simple rating mechanisms allow participants to rate every choice option equally high, which would not lead us to usable results for our analysis if no preference differences are indeed reflected by their ratings (Matzner et al. 2015). Hence, we decided not to use a simple rating mechanism for evaluating user preferences. Q-methodology is a method that is used in psychology and social sciences to rate how people think about a topic, which is why we decided not to use this method (Stephenson 1935). Instead, to identify which gamification elements users of LMSs prefer, we decided to use a MaxDiff scaling and conducted a so-called discrete choice task. More precisely, we used BWS for gaining insights into users' preferences. BWS was developed by Louviere and Woodworth (Louviere et al. 2013), and it is an extension of the MaxDiff scaling by Thurstone (1927). BWS describes a cognitive process by which survey participants repeatedly choose two objects in varying sets of three or more objects that they feel exhibit the largest perceptual difference on a described continuum of interests (Finn and Louviere 1992). In comparison to other methods, BWS has several advantages. First, it provides a high level of ranking information because each decision for a pair of attributes provides implications for the not chosen attribute (Marley and Louviere 2005; Thiebes et al. 2014). Furthermore, it is scale free, which prevents response styles and therefore does not affect the mean value and the variance obtained (Lee et al. 2013; Thiebes et al. 2014). Finally, other response biases can be avoided by using BWS (Lee et al. 2007). Overall, comparisons with other rating methods show that BWS provides better results regarding the discrimination between different attributes (Lee et al. 2007; Matzner et al. 2015). BWS relies on a classic random utility choice model that is enhanced by two contrary choices options (Louviere et al. 2013). Overall, there are three different BWS cases. In the first case, respondents have to choose between attributes. In the second case, they have to choose between different attribute levels. And in the third, they have to choose between profiles of attributes that differ by attribute levels. As indicated by the name bestworst a respondent has to choose the most and the least preferred attribute out of one choice set. By using observations obtained from all choices of every participant, preferences for each attribute (and/or level) can be calculated by using a scoring mechanism and a conditional logistic regression analysis (see next chapter). For our analysis, we decided to use case 1 of BWS. The survey results can be used to derive a preference ranking indicating the most and least preferred gamification elements. For the evaluation of BWS data, two scaling models can be used. As mentioned above, the MaxDiff model represents a cognitive process by which respondents repeatedly choose two (the most and least preferred) attributes out of a varying set of three or more objects (Finn and Louviere 1992). On the other hand, the sequential choice 
model represents a cognitive process by which respondents first have to choose the most preferred attributes and then the least preferred attributes. We evaluated the MaxDiff model for our analysis. In the following, we describe the design of our discrete choice task and explain how we implemented BWS in our survey.

\section{Task Design and Data Collection}

Before deploying the final survey, we conducted a pre-test with 15 graduate students and 20 researchers. The pre-test was intended to assess whether the survey was accurate and whether or not the questions were understandable for the participants. Apart from some typing mistakes, the participants stated that our survey is understandable. After pre-testing our survey, we applied minor changes to the wording and specified the order of appearance of gamification elements within each choice set to avoid any potential order effects. Our final survey consisted of three steps: description of gamification elements, choice task, and combination task. In addition to these tasks, we asked for demographics. In the first task, we described and visualized each gamification element in detail. In addition to the description of each element, we used a screenshot with which we visualized the elements in an LMS. In our pre-test, we found out that this kind of explanation is helpful for the participants to understand the meaning and purpose of each gamification element. To ensure that our participants are familiar with the described gamification elements, we added two questions to the first part of our survey. Besides the question whether the participants know the elements, we asked them from where they knew the gamification elements. In the choice task, each respondent was shown 10 gamification elements in 15 different choice sets. A choice set represents a varying set of four gamification elements. The choice sets were constructed due to the use of BWS for the evaluation of user preferences. In general, $2^{\mathrm{k}}$ choice sets are necessary to obtain valid results (Cohen 2003). According to this, $\mathrm{k}$ stands for the amount of attributes in the analysis. As we used 10 attributes, we would normally have to present 1024 choice sets. However, most studies use a balanced incomplete block design (BIBD), which offers a smaller amount of choice sets to receive valid results as well (Flynn et al. 2007; Lansing et al. 2013; Louviere et al. 2013; Severin et al. 2013). A BIBD is a type of design in which each choice option (i.e., gamification element) appears and co-appears equally often with each other choice option (Lee et al. 2008; Louviere et al. 2013). By using the find.BIB command in the statistical software program R, we were able to identify a sufficient amount of choice sets. According to the identified choice sets, we followed the guidelines by Orme (2005). In accordance with Orme (2005), there are four different general recommendations (Table 2) that we fulfilled. Additionally, to avoid order effects, we showed each gamification element at each position (Cohen 2003). A complete list of the identified choice sets can be seen in the appendix (Table 10). Except for the position of each gamification element, we present the appearance and the total number of elements in one choice set.

\begin{tabular}{|c|c|}
\hline \multicolumn{2}{|c|}{ Table 2. Criteria for Construction of Choice Sets } \\
\hline $\begin{array}{c}\text { Criteria by Omre (2005) } \\
\text { Displaying four or five items per choice set. } \\
\text { incremental gain. }\end{array}$ & Criteria for Our Research Paper \\
\hline $\begin{array}{c}\text { Make sure each item is displayed three or more } \\
\text { times for each respondent. }\end{array}$ & $\begin{array}{c}\text { For our analysis, we displayed four items per } \\
\text { choice set. }\end{array}$ \\
\hline Show an item just once in one choice set. & $\begin{array}{c}\text { For our analysis, we presented four different items } \\
\text { (gamification elements) in one choice set. }\end{array}$ \\
\hline For 10 or less items, stop around 15 choice sets. & $\begin{array}{c}\text { For our analysis, we used 10 items (gamification } \\
\text { elements) with 15 choice sets. }\end{array}$ \\
\hline
\end{tabular}

In the third step, we asked the participants how many and which elements they would like to have in an IS. The participants were instructed to select the gamification elements out of a list that they would like to have within a bundle. More precisely, the participants could freely choose how many and which gamification elements they would combine. Thus, we made a descriptive analysis for identifying which and how many gamification elements users of LMSs would like to combine. Hence, we used a frequency distribution to present and analyze the results of our combination analysis. More precisely, we calculated the frequency of the gamification bundles and identified the frequency of each individual gamification 
element in the constructed bundles. Finally, in the last part of our survey, we added some scales for evaluating demographic data. Therefore, we constructed our survey to identify which gamification elements IS users prefer. For that reason, we asked university students who regularly use LMSs for their participation. The respondents for the survey were recruited via a social network asking for participants who use an LMS at their university. Additionally, we sent our survey via email to several universities. In total, we were able to obtain 287 completed and usable surveys for our analysis. Overall, 145 (50.52\%) participants were female, $142(46.98 \%)$ male. The youngest participant was 17 years old and the oldest 51 years old. The participants' average age was 26 years. In the next section, we discuss the results of the BWS.

\section{Results}

\section{Results of Best-Worst Scaling}

For the analysis of our results, we used the statistical software program R. R provides several packages for the analysis of BWS results. More precisely, we made two different kinds of analyses. Therefore, we calculated a counting analysis and two kinds of conditional logistic regressions. Due to the counting analysis and the conditional logistic regression analysis, we were able to determine a ranking of all gamification elements. The results of our analyses can be seen in Table 3 .

\begin{tabular}{|c|c|c|c|c|c|c|c|c|c|}
\hline \multicolumn{10}{|c|}{ Table 3. Results of Best-Worst Scaling } \\
\hline \multicolumn{5}{|c|}{ Counting Analysis } & \multicolumn{4}{|c|}{ Conditional Logistic Regression } & \multirow[t]{3}{*}{ Rank } \\
\hline \multirow[t]{2}{*}{ Element } & \multirow[t]{2}{*}{$\mathbf{B}$} & \multirow[t]{2}{*}{$\mathbf{W}$} & \multirow[t]{2}{*}{ Mean } & \multirow[t]{2}{*}{ STD } & \multicolumn{2}{|c|}{ MaxDiff Model } & \multicolumn{2}{|c|}{$\begin{array}{l}\text { Linear Prob. } \\
\text { Model }\end{array}$} & \\
\hline & & & & & Coef. & STD & Coef. & STD & \\
\hline Level & 826 & 82 & 0.4320 & 0.3676 & 1.1367 & 0.0368 & 0.0720 & 0.0026 & 1 \\
\hline Points & 746 & 60 & 0.3983 & 0.3868 & 1.0636 & 0.0373 & 0.0663 & 0.0026 & 2 \\
\hline Goals & 752 & 99 & 0.3792 & 0.4531 & 1.0209 & 0.0375 & 0.0632 & 0.0026 & 3 \\
\hline Status & 550 & 209 & 0.1980 & 0.1980 & 0.5725 & 0.0401 & 0.0330 & 0.0026 & 4 \\
\hline Badges & 312 & 450 & -0.0801 & 0.5216 & -0.2385 & 0.0414 & -0.0133 & 0.0026 & 5 \\
\hline Leaderboard & 396 & 538 & -0.0824 & 0.6135 & -0.2454 & 0.0414 & -0.0137 & 0.0026 & 6 \\
\hline Virtual Goods & 319 & 495 & -0.1022 & 0.5644 & -0.3031 & 0.0412 & -0.0170 & 0.0026 & 7 \\
\hline Avatar & 158 & 604 & -0.259 & 0.4829 & -0.7327 & 0.0393 & -0.0431 & 0.0026 & 8 \\
\hline Time Pressure & 189 & 646 & -0.2653 & 0.5177 & -0.7490 & 0.0392 & -0.0442 & 0.0026 & 9 \\
\hline Loss Aversion & 49 & 1114 & -0.6184 & 0.3879 & \multicolumn{4}{|l|}{-} & 10 \\
\hline
\end{tabular}

With the counting analysis, we calculated a score for each gamification element for each of the 287 respondents. Therefore, we first calculated the difference between the number of times each gamification element was chosen as most preferred (best) and the number of times each gamification element was chosen as least preferred (worst). Afterwards, we divided the difference by the number of times each gamification element was shown (hence, six times) multiplied by the total number of responses (Finn and Louviere 1992; Flynn et al. 2007; Louviere et al. 2013; Severin et al. 2013). For the element level, our calculation would for example be the following: mean $=(826-82) /\left(6^{*} 287\right)=0.4320$. The resulting scale ranges from -1 to 1 . A higher score implies a higher preference and vice versa. In addition, we made two conditional logistic regressions. Marley and Louviere (2005) as well as Orme (2005) argue in their research studies that a conditional logistic regression should lead to the same results as the counting approach. Table 3 shows that the regression analysis provides the same results for the ranking positions as the counting analysis. As we needed a dependent variable for the regression analysis, we followed the 
guidelines by Flynn et al. (2007) and Hair (2010). Therefore, we used a binary coded dummy variable. More precisely, we created one observation for each possible best-worst pair per choice set per respondent. For example, if we had a choice set with points, level, avatar, and leaderboard, there would be 24 possibilities of best-worst combinations for one respondent for this choice set. As an example, the participant could choose points as best and avatar as worst. In this case, the dummy variable would be coded with 1, with the combination indicating points as best and avatar as worst; it would be coded with o for all other possibilities. The gamification elements were used as independent variables for the regression analysis. To avoid the dummy variable trap, we chose one independent variable as reference category and excluded it from our data sets (Hair 2010). We decided to exclude loss aversion, as it is the element with the lowest rank in the counting analysis. To determine whether any of the gamification elements are strongly related to the overall level of preferences for gamification elements, we examined Kendall's tau correlations between the most and least scores provided out of the counting analysis and the 10 gamification elements (Finn and Louviere 1992). The strongest positive correlation could be identified for the element level (.080), the strongest negative correlation for loss aversion (-.11). This confirms the results of our counting analysis. However, all values for Kendall's tau indicate that there is not much variation in the overall level of preferences (Finn and Louviere 1992). Overall, referring to Kendall's tau, the results of the counting analysis, and the results of the regression analysis, the four gamification elements level, points, goals, and status are positively correlated. All other gamification elements are negatively correlated. In particular, loss aversion has the strongest negative correlation in comparison to the other negatively correlated gamification elements. The total variation of our dependent variable explained by our MaxDiff regression model can be measured by $\mathrm{R}^{2}$ (Hair et al. 2010). In total, our model explains 72.93 percent $\left(\mathrm{R}^{2}=0.7293\right)$ of the variation from our dependent variable.

\section{Results of the Combination Analysis}

For answering our second research question, we added a combination section to our survey. More particularly, we wanted to find out which gamification elements users would combine to bundles in an LMS and how many gamification elements they would like to have in an LMS. Therefore, we first counted the frequency of how many gamification elements the participants included in a bundle. The results can be seen in Table 4.

\begin{tabular}{|l|l|}
\hline \multicolumn{2}{|c|}{ Table 4. Combination of Gamification Elements } \\
\hline Amount of Elements & Frequency \\
\hline 1 & 7 \\
\hline 2 & 31 \\
\hline 3 & 65 \\
\hline 4 & 80 \\
\hline 5 & 39 \\
\hline 6 & 46 \\
\hline 7 & 12 \\
\hline 8 & 7 \\
\hline Mean & $\mathbf{4 . 1 6 3 7}$ \\
\hline
\end{tabular}

The results indicate that the amount of gamification elements within a bundle varies. The participants created bundles with one, two, three, four, five, six, seven, and even eight gamification elements. Most participants would integrate 3 or 4 gamification elements into an LMS (the overall mean is 4.164, see Table 4). According to the results of the combination analysis in our survey, we identified 167 different combinations of gamification elements. Most combinations included four (48 different combinations) and three (37 different combinations) gamification elements. Twenty-four different combinations included five elements, whereas 27 combinations included six gamification elements. Ten and five different combinations included seven and eight gamification elements, respectively. 
Next, we assessed the frequency of the gamification elements in the created bundles. More precisely, to measure the frequency regarding the bundles, we counted each gamification element in the bundles in relation to the total amount of participants. The frequency of the gamification elements in the bundles is similar to the results of the BWS. From rank 1 to 7 , the order of the frequency is different to the order of the BWS. However, in both rankings, we can identify the same elements for ranks 1 to 4 with a different order (please recall that the mean value for the number of gamification elements that should be included is 4.164). The results can be seen in Table 5 .

\begin{tabular}{|l|l|l|}
\hline \multicolumn{3}{|c|}{ Table 5. Frequency of Elements in Bundles } \\
\hline \multicolumn{1}{|c|}{ Element } & Frequency (in \%) & Rank BWS \\
\hline Points & $75.61 \%$ & 2 \\
\hline Goals & $66.55 \%$ & 3 \\
\hline Level & $63.41 \%$ & 1 \\
\hline Status & $54.01 \%$ & 4 \\
\hline Leaderboard & $41.46 \%$ & 6 \\
\hline Virtual Goods & $27.87 \%$ & 7 \\
\hline Badges & $26.83 \%$ & 5 \\
\hline Avatar & $26.48 \%$ & 8 \\
\hline Time Pressure & $26.48 \%$ & 9 \\
\hline Loss Aversion & $7.67 \%$ & 10 \\
\hline
\end{tabular}

After analyzing the frequency of each gamification element, we focused on the frequency of the most preferred gamification elements in the bundles. Therefore, we focused on the most preferred bundles of three, four, five, and six gamification elements. Hence, we counted the amount of the best-ranked gamification elements status, level, points, and goals in the most preferred bundles of three to six gamification elements (see Table 6). Sixty-five participants wanted to have an element bundle consisting of three elements. Forty participants integrated points, 26 integrated level as well as goals, and only 22 integrated status regarding a bundle consisting of three gamification elements. Based on our results, 79 of our participants preferred having four elements in an LMS. Regarding this, 60 participants integrated the gamification element level as well as goals into a bundle consisting of four gamification elements. Fiftyeight participants integrated points and 45 integrated status. Regarding bundles consisting of five elements, most participants integrated points compared to level, goals, and status. However, 36 of these 39 participants included points in their bundles of five gamification elements. Thirty-one participants integrated the gamification element level as well as goals into a bundle consisting of five elements. The element status was included by 26 participants in a bundle consisting of five gamification elements. In a bundle of six gamification elements, 45 participants included points and 42 participants included goals. Thirty-eight participants integrated status and 36 integrated level into a bundle of six gamification elements.

Table 6. Frequency of Best-Ranked Elements in Bundles

\begin{tabular}{|l|c|c|c|c|}
\hline Number of Elements in a Bundle & $\mathbf{3}$ & $\mathbf{4}$ & $\mathbf{5}$ & $\mathbf{6}$ \\
\hline Number of Participants & 65 & 79 & 39 & 46 \\
\hline Level & 26 & $\mathbf{6 0}$ & 31 & 36 \\
\hline Points & $\mathbf{4 0}$ & 58 & $\mathbf{3 6}$ & $\mathbf{4 5}$ \\
\hline Goals & $\mathbf{2 6}$ & $\mathbf{6 0}$ & 31 & 42 \\
\hline Status & $\mathbf{2 2}$ & 45 & 26 & 38 \\
\hline
\end{tabular}


In a next step, we analyzed how often the four most preferred gamification elements were combined together. More precisely, we analyzed how many participants combined points, level, status, and goals in one bundle. Hence, we analyzed how often all four, three, two, and one of the most preferred gamification elements were combined within a bundle. The results can be seen in Table 7. According to our previous results, we focused on the amount of the most preferred bundles with three to six gamification elements.

\begin{tabular}{|c|c|c|c|c|c|}
\hline \multicolumn{6}{|c|}{ Table 7. Combination of Best-Ranked Elements in Bundles } \\
\hline \multicolumn{2}{|c|}{ Number of Elements in a Bundle } & 3 & 4 & 5 & 6 \\
\hline \multicolumn{2}{|c|}{ Number of Participants (total) } & 65 & 79 & 39 & 46 \\
\hline \multirow{5}{*}{ 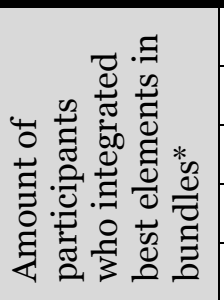 } & All four elements & o & 16 & 15 & 30 \\
\hline & At least three of the best four elements & 13 & 37 & 17 & 10 \\
\hline & At least two of the best four elements & 28 & 20 & 7 & 5 \\
\hline & At least one of the best four elements & 19 & 6 & O & 1 \\
\hline & None of the best four elements & 5 & $\mathrm{O}$ & $\mathrm{o}$ & o \\
\hline
\end{tabular}

Our previous results show that 65 participants wanted to have a bundle consisting of three gamification elements. Thirteen (20.00\%) of these 65 participants integrated three of the best four gamification elements into a bundle. More precisely, the bundles with the best-ranked elements are: status, goals, level; points, goals, level; points, status, level; points, status, goals. Further, $28(43.08 \%)$ of the 65 participants integrated two of the most preferred gamification elements into their bundles of three elements, whereas 19 (29.23\%) of the 65 participants integrated at least one of the most preferred elements. Five $(7.69 \%)$ of the 65 participants included none of the four most preferred gamification elements in their bundles of three gamification elements. Most combinations could be identified in a bundle consisting of four gamification elements. One combination integrates our four most preferred gamification elements. Sixteen (20.25\%) of these 79 participants chose the combination of goals, points, level, and status. Thirty-nine (46.84\%) of the 79 participants used at least three of the four most preferred gamification elements in their bundles consisting of four elements. Further, 20 (25.32\%) of the 79 participants used at least two of the four most preferred elements. Six (7.59\%) of 79 participants integrated at least one of the four most preferred elements. Consequently, there were no participants who included other gamification elements than the four most preferred elements in their bundles of four elements. Thirty-nine participants wanted to combine five gamification elements in an LMS. Fifteen (38.46\%) of these 39 participants integrated all four most preferred gamification elements together with a further element into a bundle consisting of five elements. Seventeen of the 39 participants integrated at least three of the four most preferred gamification elements into their bundle of five gamification elements. The remaining 7 (17.95\%) of the 39 participants included at least two of the four most preferred elements in their bundles. Finally, 46 participants wanted to combine six gamification elements in a LMS. Thirty (65.22\%) of these 46 participants integrated the four most preferred gamification elements together with two of the six other elements, and 10 (21.74\%) of the 46 participants integrated three of the four most preferred gamification elements into their bundles of six gamification elements. Furthermore, 5 (10.87\%) of the 46 participants included at least two, and one (2.17\%) of the 46 participants included one of the four most preferred gamification elements in their bundles of six elements. Again, there is no bundle without at least one of the most preferred elements. In the next chapter, we discuss our results to give precise implications for research and practice. Furthermore, we provide implications for future research.

\section{Discussion and Implications}

Previous research studies developed considerable gamification approaches but provided little guidance for considering user preferences and investigating contextual aspects. Many research approaches differ regarding the type and amount of gamification elements. In our study, we applied BWS to help consider 
which and how many gamification elements users of an LMS really want. Hereafter, we discuss the results of our research questions and implications for research and practice. Considering the research questions of our study, the key findings can be seen in Table 8.

\begin{tabular}{|c|c|}
\hline \multicolumn{2}{|c|}{ Table 8. Summary of Research Results regarding our Research Questions } \\
\hline \multirow[t]{2}{*}{$\begin{array}{l}\text { RQ1: Which gamification elements do } \\
\text { users of LMSs prefer? }\end{array}$} & $\begin{array}{l}\text { RQ2: Which gamification bundles do users } \\
\text { of LMSs prefer? }\end{array}$ \\
\hline & $\begin{array}{c}\text { RQ 2.1: How many gamification elements } \\
\text { would users of LMSs combine? }\end{array}$ \\
\hline \multirow{4}{*}{$\begin{array}{ll}\text { 1. } & \text { Level (most preferred) } \\
\text { 2. } & \text { Points } \\
\text { 3. } & \text { Goals } \\
\text { 4. } & \text { Status } \\
\text { 5. } & \text { Badges } \\
\text { 6. } & \text { Leaderboard } \\
\text { 7. } & \text { Virtual Goods } \\
\text { 8. } & \text { Avatar } \\
\text { 9. } & \text { Time Pressure } \\
\text { 10. } & \text { Loss Aversion (least preferred) }\end{array}$} & $\begin{array}{l}\text { Overall, users would implement a combination of } \\
\text { four gamification elements in an LMS (mean = } \\
\text { 4.1637). }\end{array}$ \\
\hline & $\begin{array}{l}\text { RQ 2.2: Which gamification elements } \\
\text { would users of LMSs combine? }\end{array}$ \\
\hline & $\begin{array}{l}\text { The four elements that were most frequently part } \\
\text { of the combinations were: } \\
\text { 1. Points ( } 2^{\text {nd }} \text { in overall preference) } \\
\text { 2. Goals ( } 3^{\text {rd }} \text { in overall preference) } \\
\text { 3. Level ( } 1^{\text {st }} \text { in overall preference) } \\
\text { 4. Status ( } 4^{\text {th }} \text { in overall preference) } \\
\text { Thus, even though the ranking of the frequency of } \\
\text { the part in a bundle varies slightly compared to } \\
\text { the overall preference results, users would on } \\
\text { average implement a bundle of the four top ranked } \\
\text { gamification elements in an LMS. }\end{array}$ \\
\hline & $\begin{array}{l}\text { The preferred elements were most commonly } \\
\text { integrated into the bundles. In the majority of } \\
\text { bundles, users integrated three or even all four } \\
\text { most preferred gamification elements. }\end{array}$ \\
\hline
\end{tabular}

For answering our first research question, our study produced an order of gamification elements in an LMS under consideration of user preferences. According to our results, users of LMSs prefer the gamification elements level, points, goals and status. The significantly negative correlations of the gamification elements badges, leaderboard, virtual goods, avatar, time pressure, and loss aversion indicate that users of LMSs are less concerned about these elements. Unlike our research results, existing research studies mainly used the gamification elements badges, leaderboard, and points (Davis and Singh 2015; Domínguez et al. 2013; Filsecker and Hickey 2014; Hamari 2013; Huotari and Hamari 2012; Wang and Hou 2015). In contrast to previous research results, our findings show that users of LMSs prefer intrinsically motivating gamification elements. Apart from points, all of the most preferred elements motivate users intrinsically. Therefore, current studies clarify that gamification approaches should focus more closely on intrinsic motivation. Cruz et al. (2015) explain that motivation caused by extrinsic gamification elements is just short-term. While previous research studies primarily used badges in LMSs for motivating extrinsically, our results indicate, that users of LMSs do not prefer badges. For example, Haaranen et al. (2014) evaluated that users of LMSs have strongly negative emotions towards badges. Hence, to achieve long-term effects regarding motivation, more approaches should focus on the use of intrinsically motivating gamification elements (McKernan et al. 2015). More precisely, basic psychological literature demonstrates that individuals are intrinsically motivated to fulfill activities that satisfy their basic psychological needs (Deci and Ryan 2000). However, our results indicate, that intrinsically motivating gamification elements might be more effective because elements such as levels or status clearly visualize the individual progress of LMS users (Melero et al. 2015). 
Concerning our first research question, our results suggest that users of LMSs prefer gamification elements that support them in challenging their own results by achieving a higher level or by finishing a certain goal (Melero et al. 2015; Passos et al. 2011). Contrary to our results, previous research concentrates on encouraging competition by a leaderboard, whereas our results indicate that users of LMSs do not prefer leaderboards. Competition refers to competence and the need of individuals to take part in competitions to feel more competent and efficient (Mummendey 1990). Strong competence indicates that individuals want to compare their achievements with those of others because they think that they are superior to them. More precisely, competence refers to self-presentation, which means that an individual can impress other individuals with a positive self-presentation (Mummendey 1990). According to our results, competitiveness seems to have a different role and meaning in LMSs. Sanathanam et al. (2016) analyzed the role of competition in their recent research study. They found support for the idea that effects of competition on learning outcomes vary across different competitive structures. Overall, our results indicate that users of LMSs prefer gamification elements that provide assistance in their individual learning progress without considering the progress of other users (Schöbel et al. 2016). Thus, the results of our research imply that gamification elements should be selected and designed by considering contextual aspects.

With our second research questions, we focused on the amount and combination of gamification elements in LMSs. The participants of our survey integrated one to eight gamification elements into their bundles. More precisely, the participating users of LMSs wanted to integrate four gamification elements. Referring to previous research studies, the amount of gamification elements in an LMS varies from one (Davis and Singh 2015; Fernandes et al. 2012; Hamari 2013; Jones et al. 2014; Pedro et al. 2015; Wang and Hou 2015) to six elements (Ibánez et al. 2014; Peham et al. 2014). True to the saying "less is more," our results indicate that users would prefer a combination of four gamification elements in an LMS. Regarding this, long-lasting motivational effects may be reduced by implementing a greater amount of gamification elements in LMSs (Hanus and Fox 2015). Based on the amount of gamification elements in LMSs, we evaluated which elements users of LMSs would combine. Regarding this, we could strengthen the results of our BWS. Most users integrated the gamification elements points, level, status, and goals into their bundles. More precisely, the users preferred to have at least three of the four most preferred gamification elements in their bundles of four elements. Hence, it is important to focus on the design and combination of specific gamification elements rather than on constructing an overarching game with the highest possible amount of elements (Hanus and Fox 2015).

Our research project helps us to provide theoretical and practical implications. First, we can give theoretical implications on how to implement gamification elements under consideration of user preferences in the domain of LMSs. Our results indicate that gamification element preferences might be determined by contextual and situational aspects. Users of LMSs prefer gamification elements that provide guidance for their individual learning progress regarding a certain task. Further, our results indicate that users of LMSs like to compete against themselves instead of competing against others. More precisely, using levels instead of leaderboards might be more appropriate to challenge users of LMSs in achieve better results. Therefore, gamification elements in LMSs should clearly refer to certain tasks of users by focusing on and rewarding the individual success of users. According to our results, the importance of experiences that are intrinsically motivating, meaning enjoyable, might dominate as predictors of better learning outcomes. From a practical perspective our findings indicate that LMSs can be optimized by gamification elements based on the needs and preferences of users. Organizations and gamification project managers must understand the potential of gamification to develop the skills of LMS users to lead them to better learning outcomes. In many cases, gamification is not working because most gamification projects focus on obvious gamification elements such as badges, leaderboards, and points rather than the more subtle game design that considers contextual aspects as well as the needs of the target group (Fleming 2014). Referring to this, our results indicate that gamification elements should be designed under consideration of contextual aspects to make the system use more engaging for the target audience. Hence, gamification designers should consider a gamification element design that visualizes the individual learning progress of users. For constructing a gamified LMS, gamification designers should integrate a maximum of four gamification elements. Having a large number of gamification elements might have contrary effects on motivation and learning outcomes (Hanus and Fox 2015). Furthermore, gamification designers should consider that gamification elements such as time pressure or loss aversion 
might work in daily life but not in a LMS. Hence, such elements should not be used because they distract users from their learning activity.

\section{Limitations and Future Research}

This study is not without limitations, which provides implications for future research. Relating to the survey participants, we focused on university students. Therefore, the average age was 26 years. Hence, further analyses should consider employees of various ages from companies that use LMSs. Additionally, we focused on LMSs. That is why we should have a closer look on different kinds of IS (Hess et al. 2014). Furthermore, we did not consider gamification dynamics and motives such as achievements or challenges (Blohm and Leimeister 2013). Finally, we conducted an online survey for analyzing user preferences regarding gamification. Hence, it is necessary to implement gamification elements in an LMS for evaluating user preferences.

However, the limitations of our research paper deliver several implications for future research. Our first step will be an analysis of the differences in relation to demographic data. Several studies indicate that women and men prefer different gamification elements (Koivisto and Hamari 2014). We will analyze the role and meaning of age with regard to gamification element preferences and combinations, too (Koivisto and Hamari 2014; Lepper et al. 2005). Our survey was carried out in universities, which is why the average age is 26 years. Thus, we will conduct our survey in companies that use LMSs. Since individuals can be motivated differently, we will identify and analyze different kinds of groups with regard to the individual motivations of LMS users (Deci et al. 1994; Deci et al. 2001; Deci and Ryan 2000). Using the results of the survey, we will obtain new insights into what kind of motivational structures determine which gamification elements users of LMSs prefer. Future analyses should focus on the adaption of gamification elements to the cooperative and competitive structures of users by considering their preferences (Schöbel and Söllner 2016). Santhanam et al. (2016) suggest that it is necessary to isolate the effects of different competitive structures because not all competitions are the same and there may be no one-size-fits-all solution. Additionally, future research should analyze the possibilities presented by cooperative dynamics to strengthen the relationship between users of LMSs (Wilson et al. 2016). Liu et al. (2013) point out that very little research has considered the cooperative, competitive, and cooperativecompetitive design of gamification elements. This comes along with further research on the combination of cooperative and competitive gamification elements. Future research could determine whether adding cooperative elements makes competitive elements more engaging and enjoyable than using cooperative or competitive elements alone (Liu et al. 2013). Therefore, studies should analyze the meaning of cooperation and competition in the context of learning (Wilson et al. 2016).

Finally, we want to implement the gamification elements in an LMS under consideration of user preferences. Our long-term goal is to analyze the effects on user motivation, system use (Söllner et al. 2016), and learning outcomes achieved by gamification elements that are adapted to the preferences and individual motivation structures of LMS users.

\section{Conclusion}

This study analyzed and tested which gamification elements users of LMSs prefer. The ranking from 1 (most preferred gamification element) to 10 (least preferred gamification element) is as follows: level, points, goals, status, badges, leaderboard, virtual goods, avatar, time pressure, loss aversion. Gamification elements are always combined to bundles. Referring to this, our research study tested which and how many gamification elements users would combine in an LMS. Therefore, we included a further analysis. We asked our participants to indicate which and how many gamification elements they would integrate into an LMS. Referring to the results of the combination analysis, we could strengthen the results of the BWS. With BWS, we identified the four elements level, points, status, and goals as the most preferred gamification elements. The most frequently used gamification elements in the bundles are the same. On the basis of our research findings, we were able to provide precise implications for research and practice. Therefore, our research recommends to integrate gamification elements into LMSs that focus on the individual learning progress of users without considering the progress of other users. Given the immense growth of gamification projects and the potential of motivating users by games, more research on this topic is guaranteed. 


\section{Acknowledgements}

The research presented in this paper was funded by the German Federal Ministry of Education and Research in the project StaySmart (www.projekt-staysmart.de), FK 01FK14008, and the project kuLtig (www.projekt-kuLtig.de), FK 01BEXo5A13.

\section{References}

Alavi, M., and Leidner, D. E. 2001. "Research commentary: Technology-mediated learning-A call for greater depth and breadth of research," Information Systems Research (12:1), pp. 1-10.

Aparicio, A. F., Gutiérres Vela, F. L., Gonzáles Sánchez, J. L., and Isla Montes, J. L. 2012. "Analysis and application of gamification," Proceedings of the 13th International Conference on Interaccion Persona-Ordenador .

Arbaugh, J. B. 2000. "How classroom environment and student engagement affect learning in Internetbased MBA courses," Business Communication Quarterly (63:4), pp. 9-26.

Attali, Y., and Areli-Attali, M. 2015. "Gamification in assessment: Do points affect test performance," Computers \& Education (83), pp. 57-63.

Bacon, D. R. 2003. “A comparison of approaches to importance-performance analysis," International Journal of Market Research (45:1), pp. 55-73.

Bedwell, W. L., Pavlas, D., Heyne, K., Lazzara, E. H., and Salas, E. 2012. "Toward a Taxonomy Linking Game Attributes to Learning: An Empirical Study," Simulation \& Gaming (43:6), pp. 729-76o.

Biro, G. I. 2013. "Ready, Study, Share: An Inquiry Into the Didactic Approach of Gamification With a Special View to the Possible Application in Higher Education," European Scientific Journal , pp. 341345 .

Blohm, I., and Leimeister, J. M. 2013. "Gamification: Design of IT-based enhancing services for motivational support and behavioral change," Business \& Information Systems Engineering (BISE) (5:4), pp. 275-278.

Boticki, I., Baksa, J., Seow, P., and Looi, C.-K. 2015. "Usage of a mobile social learning platform with virtual badges in primary school," Computers \& Education (86), pp. 120-136.

Bunchball, I. 2010. "Gamification 101: An Introduction to the Use of Game Dynamics to Influence Behavior," (White Paper). Bunchball Inc .

Burgers, C., Eden, A., van Engelenburg, M. D., and Buningh, S. 2015. "How feedback boosts motivation in play in a brain-training game," Computers in Human Behavior (48), pp. 94-103.

Cheng, M.-T., Lin, Y.-W., and She, H.-C. 2015. "Learning through playing Virtual Age: Exploring the interactions among student concept learning, gaming performance, in-game behaviors, and the use of in-game characters," Computers \& Education (86), pp. 18-29.

Christy, K. R., and Fox, J. 2014. "Leaderboards in a virtual classroom: A test of stereotype threat and social comparison explanations for women's math performance," Computers \& Education (78), pp. 66-77.

Cohen, S. H. 2003. "Maximum Difference Scaling: Improved Measures of Importance and Preferences for Segmentation," Sawtooth Research Paper Series , pp. 1-17.

Connolly, T. M., Boyle, E. A., MacArthur, E., Hainey, T., and Boyle, J. M. 2012. "A systematic literature review of empirical evidence on computer games and serious games," Computers \& Education (59:2), pp. 661-686.

Cramer, H., Rost, M., and Holmquist, L. E. 2011. "Performing a check-in: emerging practices, norms and'conflicts' in location-sharing using foursquare," Proceedings of the 13th International Conference on Human Computer Interaction with Mobile Devices and Services , pp. 57-66.

Cruz, C., Hanus, M. D., and Fox, J. 2015. "The need to achieve: Players' perceptions and uses of extrinsic meta-game reward systems for video game consoles," Computers in Human Behavior, pp. 1-9.

Davis, K., and Singh, S. 2015. "Digital badges in afterschool learning: Documenting the perspectives and experiences of students and educators," Computers \& Education (88), pp. 72-83.

de Santana, Sivaldo J. de, Souza, H. A., Florentin, V. A. F., Paiva, R., Bittencourt, I. I., and Isotani, S. 2016. "A Quantitative Analysis of the Most Relevant Gamification Elements in an Online Learning Environment," Proceedings of the 25th International Conference Companion on World Wide Web, pp. 911-916. 
Deci, E. L., Eghrari, H., Patrick, B. C., and Leone, D. R. 1994. "Facilitating Internalization: The SelfDetermination Theory Perspective," Journal of Personality (62:1), pp. 119-142.

Deci, E. L., and Ryan, R. M. 2000. "The "What" and "Why" of Goal Pursuits: Human Needs and the SelfDetermination of Behavior," Psychological Inquiry (11:4), pp. 227-268.

Deci, E. L., Ryan, R. M., Gagne, M., Leone, D. R., Usunov, J., and Kornazheva, B. P. 2001. "Need Satisfaction, Motivation, and Well-Being in the Work Organizations of a Former Eastern Bloc Country: A Cross-Cultural Study of Self-Determination," Personality and Social Psychology Bulletin (27:8), pp. 930-942.

de-Marcos, L., Garcia-Lopez, E., and Garcia-Cabot, A. 2016. "On the Effectiveness of Game-like and Social Approaches in Learning: Comparing Educational Gaming, Gamification \& Social Networking," Computers \& Education (95), pp. 99-113.

Demetrovics, Z., Urbán, R., Nagygyörgy, K., Farkas, J., Zilahy, D., Mervó, B., Reindl, A., Ágoston, C., Kertész, A., and Harmath, E. 2011. "Why do you play? The development of the motives for online gaming questionnaire (MOGQ)," Behavior research methods (43:3), pp. 814-825.

Deterding, S., Dixon, D., Khaled, R., and Nacke, L. 2011. "From Game Design Elements to Gamefulness: Defining "Gamification"," Proceedings of the 15th International Academic MindTrek Conference Envisioning Future Media Environments , pp. 9-15.

Domínguez, A., Saenz-de-Navarrete, J., de-Marcos, L., Fernández-Sanz, L., Páges, C., and MartínezHerráiz, J.-J. 2013. "Gamifying learning experiences: Practical implications and outcomes," Computers \& Education (63), pp. 380-392.

Evans, C., and Gibbons, N. J. 2007. "The interactivity effect in multimedia learning," Computers \& Education (49:4), pp. 1147-1160.

Faghihi, U., Brautigam, A., Jorgenson, K., Martin, D., Brown, A., Measures, E., and Maldonado-Bouchard, S. 2014. "How Gamification Applies for Educational Purpose Specially with College Algebra," Procedia Computer Science (41), pp. 182-187.

Fernandes, J., Duarte, D., Ribeiro, C., Farinha, C., Madeiras Pereira, J., and Mira da Silva, M. 2012. "iThink: A game-based approach towards improving collaboration and participation in requirement elicitation," Procedia Computer Science (15), pp. 66-77.

Filsecker, M., and Hickey, D. T. 2014. "A multilevel analysis of the effects of external rewards on elementary students' motivation, engagement and learning in an educational game," Computers \& Education (75), pp. 136-148.

Finn, A., and Louviere, J. J. 1992. "Determining the Appropriate Response to Evidence of Public Concern: The Case of Food Safety," Journal of Public Policy \& Marketing (11:1), pp. 12-25.

Fleming, N. 2014. Gamification: Is it game over? http://www.bbc.com/future/story/20121204-cangaming-transform-your-life. Accessed 17 August 2016.

Flynn, T. N., Louviere, J. J., Peters, T. J., and Coast, J. 2007. "Best-worst scaling: What it can do for health care research and how to do it," Journal of Health Economics (26:1), pp. 171-189.

Fogel, G. 2015. Will 80\% of gamification projects fail? Giving credit to Gartner's 2012 gamification forecast. http://www.gameffective.com/gamification-basics/will-80-of-gamification-projects-fail/. Accessed 17 August 2016.

Gartner 2012. Gartner Says by 2014, 8 o Percent of Current Gamified Applications Will Fail to Meet Business Objectives Primarily Due to Poor Design. http://www.gartner.com/newsroom/id/2251015. Accessed 17 August 2016.

Green, P. E., and Srinivasan, V. 1990. "Conjoint analysis in marketing: new developments with implications for research and practice," The Journal of Marketing , pp. 3-19.

Gupta, S., and Bostrom, R. P. 2009. "Technology-mediated learning: A comprehensive theoretical model," Journal of the Association for Information Systems (10:9), pp. 686-714.

Haaranen, L., Ihantola, P., Hakulinen, L., and Korhonen, A. 2014. "How (not) to introduce badges to online exercises," Proceedings of the 45th ACM technical symposium on Computer science education $(A C M)$, pp. 33-38.

Hair, J. F. 2010. "Multivariate data analysis," Pearson College Division .

Hair, J. F., Black, W. C., Babin, B. J., and Anderson, R. E. 2010. Multivariate Data Analysis. A Global Perspective, New Jersey: Pearson.

Hamari, J. 2013. "Transforming homo economicus into homo ludens: A field experiment on gamification in a utilitarian peer-to-peer trading service," Electronic Commerce Research and Applications (12:4), pp. 236-245. 
Hamari, J., Koivisto, J., and Sarsa, H. 2014. "Does Gamification Work?: A Literature Review of Empirical Studies on Gamification," Hawaii International Conference on System Science, pp. 3025-3034.

Hamari, J., Shernoff, D. J., Rowe, E., Coller, B., Asbell-Clarke, J., and Edwards, T. 2016. "Challenging games help students learn: An empirical study on engagement, flow and immersion in game-based learning," Computers in Human Behavior (54), pp. 170-179.

Hanus, M. D., and Fox, J. 2015. "Assessing the effects of gamification in the classroom: A longitudinal study on intrinsic motivation, social comparison, satisfaction, effort and, academic performance," Computers \& Education (80), pp. 152-161.

Hess, T. J., McNab, A. L., and Basoglu, K. A. 2014. "Reliability Generalization of Perceived Ease of Use, Perceived Usefulness, and Behavioral Intentions," MIS Quarterly (38:1), pp. 1-28.

Hew, K. F., Huang, B., Chu, K. W. S., and Chiu, D. K. W. 2016. "Engaging Asian students through game mechanics: Findings from two experiment studies," Computers \& Education (92), pp. 221-236.

Hsu-Hwa, S., Chang, J.-W., and Lee, C.-C. 2013. "Designing Attractive Gamification Features for Collaborative Storytelling Websites," Cyberpsychology, Behavior, and Social Networking (16:6), pp. 428-435.

Huotari, K., and Hamari, J. 2012. “Defining Gamification - A Service Marketing Perspective," Proceedings of the 16th International Academic MindTrek Conference , pp. 17-22.

Ibánez, M.-B., Di-Serio, Á., and Delgado-Kloos, C. 2014. "Gamification for Engaging Computer Science Students in Learning Activities: A Case Study," IEEE Transactions on Learning Technologies (7:3), pp. 291-301.

Jones, B. A., Madden, G. J. M., Wengreen, and Heidi J. 2014. "The FIT Game: Preliminary evaluation of a gamification approach to increasing fruit and vegetable consumption in school," Preventive Medicine (68), pp. 76-79.

Koivisto, J., and Hamari, J. 2014. "Demographic differences in perceived benefits from gamification," Computer in Human behavior (35), pp. 179-188.

Lafrenière, M.-A. K., Verner-Filion, J., and Vallerand, R. J. 2012. "Development and validation of the Gaming Motivation Scale (GAMS)," Personality and Individual Differences (53:7), pp. 827-831.

Lansing, J., Schneider, S., and Sunyaev, A. 2013. "Cloud Service Certification: Measuring Consumers' Preferences For Assurances," European Conference on Information Systems , pp. 1-12.

Lee, J. A., Soutar, G., and Louviere, J. J. 2008. "The best-worst scaling approach: An alternative to Schwartz's values survey," Journal of personality assessment (90:4), pp. 335-347.

Lee, J. A., Soutar, G. N., and Louviere, J. 2007. "Measuring values using best-worst scaling: The LOV example," Psychology \& Marketing (24:12), pp. 1043-1058.

Lee, J. J., Ceyhan, P., Jordan-Cooley, W., and Sung, W. 2013. "GREENIFY: A Real-World Action Game for Climate Change Education,” Simulation \& Gaming (44:2-3), pp. 349-365.

Lepper, M. R., Corpus, J. H., and Iyengar, S. S. 2005. "Intrinsic and extrinsic motivational orientations in the classroom: Age differences and academic correlates," Journal of Educational Psychology (97:2), pp. 184-196.

Li, W., Grossman, T., and Fitzmaurice, G. 2012. "GamiCAD: a gamified tutorial system for first time autocad users," Proceedings of the 25th annual ACM symposium on User interface software and technology , pp. 103-112.

Liu, D., Li, X., and Santhanam, R. 2013. "Digital Games and Beyond: What Happens When Players Compete," MIS Quarterly (37:1), pp. 111-124.

Liu, Y., Alexandrova, T., and Nakajima, T. 2011. "Gamifying intelligent environments," Proceedings of the 2011 international ACM workshop on Ubiquitous meta user interfaces , pp. 7-12.

Louviere, J. J., Lings, I., Islam, T., Gudergan, S., and Flynn, T. 2013. "An introduction to the application of (case 1) best-worst scaling in marketing research," International Journal of Research in Marketing (30), pp. 292-303.

Marley, A. A. J., and Louviere, J. J. 2005. "Some probabilistic models of best, worst, and best-worst choices," Journal of Mathematical Psychology (49:6), pp. 464-480.

Mason, A. D., Michalakidis, G., and Krause, P. J. 2012. "Tiger nation: Empowering citizen scientists," 6th International Conference on Digital Ecosystems and Technologies , pp. 1-5.

Matzner, M., Hoffen, M. von, Heide, T., Plenter, F., and Chasin, F. 2015. "A Method for Measuring User Preferences in Information Systems Design Choices," European Conference on Information Systems , pp. 1-16. 
McKernan, B., Martey, R. M., Stromer-Galley, J., Kenski, K., Clegg, B. A., Folkestad, J. E., Rhodes, M. G., Shaw, A., Saulnier, E. T., and Strzalkowski, T. 2015. "We don't need no stinkin'badges: The impact of reward features and feeling rewarded in educational games," Computers in Human Behavior (45), pp. 299-306.

Mekler, E. D., Brühlmann, F., Tuch, A. N., and Opwis, K. 2015. "Towards understanding the effects of individual gamification elements on intrinsic motivation and performance," Computers in Human Behavior , pp. 1-10.

Melero, J., Hernándes-Leo, D., and Manatunga, K. 2015. "Group-based mobile learning: Do group size and sharing mobile devices matter?” Computers in Human Behavior (44), pp. 377-385.

Mummendey, H. D. 1990. Psychologie der Selbstdarstellung, Göttingen.

Orme, B. 2005. "Accuracy of HB Estimation in MaxDiff Experiments," Sawtooth Research Paper Series , pp. $1-7$.

Passos, E. B., Medeiros, D. B., Neto, P. A. S., and Clua, E. W. G. 2011. "Turning Real-World Software Development into a Game," Proceedings of SBGames , pp. 260-269.

Pedro, L., Santos, Carlos, Aresta, Mónica, and Almeida, S. 2015. "Peer-supported badge attribution in a collaborative learning platform: A SAPO campus case," Computers in Human Behavior (51), pp. 562567.

Peham, M., Breitfuss, G., and Michalczuk, R. 2014. "The "ecoGator" App: Gamification for Enhanced Energy Efficiency in Europe," Proceedings of the Second International Conference on Technological Ecosystems for Enhancing Multiculturality. ACM , pp. 179-183.

Perry, B. 2015. "Gamifying French Language Learning: a case study examining a quest-based, augmented reality mobile learning-tool," Procedia-Social and Behavioral Sciences (174), pp. 2308-2315.

Santhanam, R., Liu, D., and Wei-Cheng, M. S. 2016. "Gamification of Technology-Mediated Training: Not All Competitions are the Same," Information Systems Research , pp. 1-13.

Scheiner, C. W. 2015. "The Motivational Fabric of Gamified Idea Competition: The Evaluation of Game Mechanics from a Longitudinal Perspective," Creativity and Innovation Management (24:2), pp. 341-352.

Scheiner, C. W., and Witt, M. 2013. "The Backbone of Gamification: A Theoretical Consideration of Play and Game Mechanics," GI-Jahrestagung , pp. 2372-2386.

Schlagenhaufer, C., and Amberg, M. 2015. "A Descriptive Literature Review and Classification Framework for Gamification in Information Systems," European Conference on Information Systems .

Schöbel, S., Lehmann, K., and Oeste-Reiß, Sarah, Söllner, Matthias 2016. "StaySmart - Individuelles und kompetenzorientiertes E-Learning im Zeitalter des demografischen Wandels," e-Learning Fachtagung Informatik (DeLFI) .

Schöbel, S., and Söllner, M. 2016. "How to Gamify Information Systems - Adapting Gamification to Individual User Preferences," European Conference on Information Systems (ECIS) .

Seaborn, K., and Fels, D. I. 2015. "Gamification in theory and action: A survey," International Journal of Human-Computer Studies (74), pp. 14-31.

Severin, F., Schmidtke, J., Mühlbacher, A., and Rogowski, W. H. 2013. "Eliciting preferences for priority setting in genetic testing: a pilot study comparing best-worst scaling and discrete-choice experiment," European Journal of Human Genetics (21:11), pp. 1202-1208.

Shang, S. S. C., and Lin, K. Y. 2013. "An Understanding of the Impact of Gamification on Purchase Intentions," Americas Conference on Information Systems , pp. 1-11.

Shi, L., and Cristea, A. I. 2016. "Motivational Gamification Strategies Rooted in Self-Determination Theory for Social Adaptive E-Learning," International Conference on Intelligent Tutoring Systems , pp. 294-300.

Shute, V. J., D'Mello, S., Baker, R., Cho, K., Bosch, N., Ocumpaugh, J., Ventura, M., and Almeda, V. 2015. "Modeling how incoming knowledge, persistence, affective states, and in-game progress influence student learning from an educational game," Computers \& Education (86), pp. 224-235.

Sigala, M. 2015. "The application and impact of gamification funware on trip planning and experiences: The case of TripAdvisor's funware," Electronic Markets (25:3), pp. 189-209.

Silpasuwanchai, C., Ma, X., Shigemasu, H., and Ren, X. 2016. "Developing a Comprehensive Engagement Framework of Gamification for Reflective Learning," Proceedings of the 2016 ACM Conference on Designing Interactive Systems , pp. 459-472.

Simoes, J., Díaz Redondo, R., and Fernández Vilas, A. 2013. "A social gamification framework for K-6 learning platform," Computers in Human Behavior (29:2), pp. 345-353. 
Sims, R. 2003. "Promises of interactivity: Aligning learner perceptions and expectations with strategies for flexible and online learning," Distance Education (24:1), pp. 87-103.

Smith, A.-L., and Baker, L. 2011. "Getting a clue: creating student detectives and dragon slayers in your library,” Reference Services Review (39:4), pp. 628-642.

Söllner, M., Hoffmann, A., and Leimeister, J. M. 2016. "Why Different Trust Relationships Matter for Information Systems Users," European Journal of Information Systems (EJIS) (3:25), pp. 274-287.

Stapleton, A. J. 2004. "Serious games: Serious opportunities," Austrailan Game Developers' Conference , pp. $1-5$.

Stephenson, W. 1935. "Correlating persons instead of tests," Journal of Personality (4:1), pp. 17-24.

Thiebes, S., Lins, S., and Basten, D. 2014. "Gamifying Information Systems: A Synthesis of Gamification Mechanics and Dynamics," European Conference on Information Systems .

Thurstone, L. L. 1927. “A Law of Comparative Judgement,” Psychological Review (34:9), pp. 273-286.

Turabik, T., and Baskan, G. A. 2015. "The Importance of Motivation Theories in Terms Of Education Systems," Procedia-Social and Behavioral Sciences (186), pp. 1055-1063.

Urh, M., Vukovic, G., and Jereb, E. 2015. "The model for introduction of gamification into e-learning in higher education," Procedia-Social and Behavioral Sciences (197), pp. 388-397.

Usami, H., Eguchi, H., Ozaki, M., and Adachi, Y. 2015. "Development of Web Learning Support System using "My Dictionary" in English Study," Procedia Computer Science (60), pp. 944-951.

Wang, W.-T., and Hou, Y.-P. 2015. "Motivations of employees' knowledge sharing behaviors: A selfdetermination perspective," Information and Organization (25:1), pp. 1-26.

Wang Alf, I. 2015. "The wear out effect of a game-based student response system," Computers \& Education (82), pp. 217-227.

Wilson, D., Calongne, C., and Henderson, S. B. 2016. "Gamification Challenges and a Case Study in Online Learning," Internet Learning (4:2), pp. 84-102.

Wouters, P., van Nimwegen, C., van Oostendorp, H., and Van Der Spek, Erik D. 2013. "A meta-analysis of the cognitive and motivational effects of serious games," Journal of Educational Psychology (105:2), pp. 1-17.

Zaman, B., Poels, Y., Sulmon, N., Annema, J.-H., Verstraete, M., Grooff, D. de, Cornillie, F., and Desmet, P. 2012. "Concepts and Mechanics for Educational Mini-Games," International Journal on Advances in Intelligent Systems Volume 5, Number 3 \& 4, 2012 (5:3\&4), pp. 567-576.

Zyda, M. 2005. "From visual simulation to virtual reality to games," Computer Society (38:9), pp. 25-32. 


\section{Appendix}

\begin{tabular}{|c|c|c|c|c|c|c|c|c|c|c|c|c|c|c|c|c|c|c|}
\hline \multicolumn{19}{|c|}{ Table 9. Literature Review } \\
\hline Author & 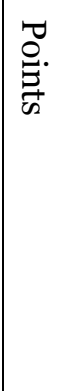 & $\begin{array}{l}\Omega \\
0 \\
\ddot{d} \\
\tilde{D}\end{array}$ & 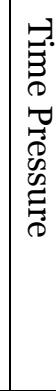 & $\begin{array}{l}5 \\
8 \\
0 \\
0 \\
2 \\
2 \\
9 \\
9 \\
0.0 \\
0 \\
0\end{array}$ & 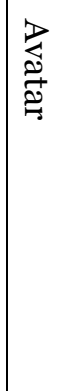 & $\begin{array}{l}-5 \\
0 \\
0 \\
0\end{array}$ & $\begin{array}{l}5 \\
0 \\
0 \\
0 \\
0 \\
0 \\
0 \\
0 \\
0 \\
0\end{array}$ & 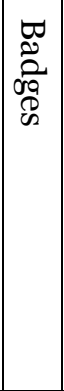 & 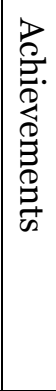 & 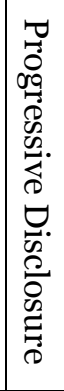 & 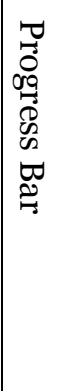 & 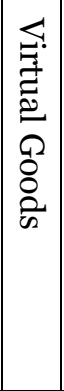 & 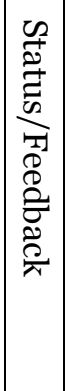 & 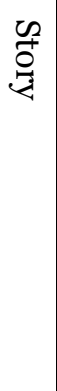 & 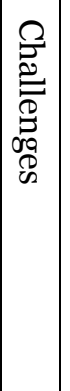 & 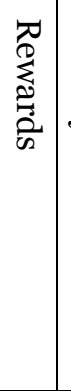 & 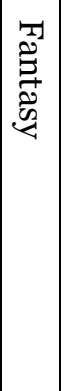 & 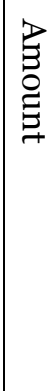 \\
\hline Hamari et al. (2016) & & & & & & $\mathrm{X}$ & & & & & & & & & $\mathrm{X}$ & & & 2 \\
\hline Shi and Cristea (2016) & & $\mathrm{X}$ & & & & & & & & & & & $\mathrm{X}$ & & & & & 2 \\
\hline Wang (2015) & & & $\mathrm{X}$ & & & & & & & & & & $\mathrm{X}$ & & & & & 2 \\
\hline Faghihi et al. (2014) & $\mathrm{X}$ & & & & & & & $\mathrm{X}$ & & & & & & & & & & 2 \\
\hline Manson et al. (2012) & $\mathrm{X}$ & & & & & & & $\mathrm{X}$ & & & & & & & & & & 2 \\
\hline Burgers et al. (2015) & & & $\mathrm{X}$ & & $\mathrm{X}$ & & & & & & & & $\mathrm{X}$ & & & & & 3 \\
\hline Boticki et al. (2015) & $\mathrm{X}$ & & & & $\mathrm{X}$ & & & $\mathrm{X}$ & & & & & & & & & & 3 \\
\hline \begin{tabular}{|l|} 
Perry (2015) \\
\end{tabular} & $\mathrm{X}$ & & & & & & & $\mathrm{X}$ & & & & & & & $\mathrm{X}$ & & & 3 \\
\hline Attali and Arieli-Attali (2015) & $\mathrm{X}$ & & & & & & & & & & & & $\mathrm{X}$ & & & $\mathrm{X}$ & & 3 \\
\hline Cramer et al. (2011) & $\mathrm{X}$ & & & & & & & $\mathrm{X}$ & & & & & $\mathrm{X}$ & & & & & 3 \\
\hline Shute et al. (2015) & $\mathrm{X}$ & $\mathrm{X}$ & & & & & & $\mathrm{X}$ & & $\mathrm{X}$ & & & & & & & & 3 \\
\hline Silpasuwanchai et al. (2016) & $\mathrm{X}$ & & & & & & $\mathrm{X}$ & $\mathrm{X}$ & & & & & & & & & & 3 \\
\hline Hew et al. (2016) & $\mathrm{X}$ & & & & & & $\mathrm{X}$ & $\mathrm{X}$ & & & & & & & & & & 3 \\
\hline Hanus and Fox (2015) & & & & & & & $\mathrm{X}$ & $\mathrm{X}$ & & & & $\mathrm{X}$ & & & & & & 3 \\
\hline Mekler et al. (2015) & $\mathrm{X}$ & & & & & $\mathrm{X}$ & $\mathrm{X}$ & & & & & & & & & & & 3 \\
\hline Dominguez et al. (2013) & & & & & & & $\mathrm{X}$ & $\mathrm{X}$ & $\mathrm{X}$ & & & & & & & & & 3 \\
\hline Melero et al. (2015) & $\mathrm{X}$ & & & & $\mathrm{X}$ & $\mathrm{X}$ & & & & & & & & & & $\mathrm{X}$ & & 4 \\
\hline Smith and Baker (2011) & $\mathrm{X}$ & $\mathrm{X}$ & & & $\mathrm{X}$ & & & & & & & $\mathrm{X}$ & & & & & & 4 \\
\hline Santhanam et al. (2016) & & & & & & $\mathrm{X}$ & & & $\mathrm{X}$ & & & $\mathrm{X}$ & & & $\mathrm{X}$ & & & 4 \\
\hline Usami et al. (2015) & $\mathrm{X}$ & & & & & & $\mathrm{X}$ & $\mathrm{X}$ & $\mathrm{X}$ & & & & & & & & & 4 \\
\hline Cheng et al. (2015) & $\mathrm{X}$ & & & & $\mathrm{X}$ & $\mathrm{X}$ & & & & & & & $\mathrm{X}$ & & & & & 4 \\
\hline Santana et al. (2016) & $\mathrm{X}$ & & & & & & $\mathrm{X}$ & $\mathrm{X}$ & $\mathrm{X}$ & & & & & & & & & 4 \\
\hline Christy and Fox (2014) & $\mathrm{X}$ & & & & & $\mathrm{X}$ & $\mathrm{X}$ & & & $\mathrm{X}$ & & & & $\mathrm{X}$ & & & & 5 \\
\hline Peham et al. (2014) & $\mathrm{X}$ & & & & & $\mathrm{X}$ & $\mathrm{X}$ & & & & & $\mathrm{X}$ & $\mathrm{X}$ & & & & & 5 \\
\hline Ibánez et al. (2014) & $\mathrm{X}$ & $\mathrm{X}$ & & & & & $\mathrm{X}$ & $\mathrm{X}$ & $\mathrm{X}$ & & & & & & & & & 5 \\
\hline Liu et al. (2013) & & & $\mathrm{X}$ & $\mathrm{X}$ & & $\mathrm{X}$ & & & & & & & $\mathrm{X}$ & & $\mathrm{X}$ & & & 5 \\
\hline Filsecker and Hickey (2014) & & $\mathrm{X}$ & & & $\mathrm{X}$ & & $\mathrm{X}$ & $\mathrm{X}$ & $\mathrm{X}$ & $\mathrm{X}$ & & & & & & & & 6 \\
\hline Li et al. (2012) & & $\mathrm{X}$ & $\mathrm{X}$ & & & & & & & & & & $\mathrm{X}$ & $\mathrm{X}$ & & $\mathrm{X} \mid \mathrm{I}$ & $\mathrm{X}$ & 6 \\
\hline Simoes et al. (2013) & $\mathrm{X}$ & & & & & & $\mathrm{X}$ & $\mathrm{X}$ & $\mathrm{X}$ & & $\mathrm{X}$ & $\mathrm{X}$ & & & & $\mathrm{X}$ & & 7 \\
\hline Liu et al. (2011) & $\mathrm{X}$ & & & $\mathrm{X}$ & & $\mathrm{X}$ & $\mathrm{X}$ & $\mathrm{X}$ & & & & $\mathrm{X}$ & & & & $\mathrm{X}$ & & 7 \\
\hline Total & 20 & 6 & 4 & 2 & 6 & 9 & 13 & 16 & 7 & 3 & 1 & 6 & 9 & 2 & 4 & \begin{tabular}{|l|l}
5 & 1 \\
\end{tabular} & 1 & \\
\hline
\end{tabular}




\begin{tabular}{|c|c|c|c|c|c|c|c|c|c|c|c|c|c|c|c|c|}
\hline \multicolumn{17}{|c|}{ Table 10. Design for Choice Sets } \\
\hline \multirow{2}{*}{$\begin{array}{l}\text { Gamification } \\
\text { Elements }\end{array}$} & \multicolumn{15}{|c|}{ Choice Set Number } & \multirow{2}{*}{ Appearances } \\
\hline & 1 & 2 & 3 & 4 & 5 & 6 & 7 & 8 & 9 & 10 & 11 & 12 & 13 & 14 & 15 & \\
\hline Level & 0 & 1 & O & O & O & 1 & O & O & 1 & 0 & 1 & o & 1 & 1 & $\mathrm{O}$ & 6 \\
\hline Points & $\mathrm{O}$ & 1 & o & 1 & 1 & O & o & 1 & o & 0 & 1 & 1 & 0 & 0 & $\mathrm{O}$ & 6 \\
\hline Goals & 1 & 0 & 1 & O & 1 & 0 & O & 1 & O & 0 & 0 & $\mathrm{O}$ & 1 & 0 & 1 & 6 \\
\hline Status & 1 & 1 & o & 0 & O & 1 & 1 & o & o & 1 & 1 & 0 & 0 & 0 & 0 & 6 \\
\hline Badges & 1 & 0 & o & O & O & 0 & 1 & o & 1 & 0 & 0 & 1 & $\mathrm{O}$ & 1 & 1 & 6 \\
\hline Leaderboard & 0 & 0 & 0 & 1 & 1 & 0 & 1 & 1 & 0 & 1 & 1 & 0 & 0 & 0 & $\mathrm{O}$ & 6 \\
\hline Virtual Goods & 1 & 0 & 1 & 1 & O & 1 & O & o & 1 & 1 & 0 & $\mathrm{O}$ & 0 & 0 & $\mathrm{O}$ & 6 \\
\hline Avatar & 0 & 0 & 1 & O & 1 & 0 & 0 & o & 0 & 1 & 0 & 1 & 1 & 0 & 1 & 6 \\
\hline Time Pressure & 0 & 0 & 1 & 1 & o & 0 & 1 & o & o & 0 & 0 & 1 & 0 & 1 & 1 & 6 \\
\hline Loss Aversion & 0 & 1 & o & 0 & $\mathrm{O}$ & 1 & o & 1 & 1 & 0 & 0 & 0 & 1 & 1 & 0 & 6 \\
\hline $\begin{array}{l}\text { Total Number } \\
\text { of Elements in } \\
\text { Set }\end{array}$ & 4 & 4 & 4 & 4 & 4 & 4 & 4 & 4 & 4 & 4 & 4 & 4 & 4 & 4 & 4 & \\
\hline
\end{tabular}

